\title{
Diagnose of Air Quality by Laser Sensing Technique
}

\author{
Yoshizumi KAJII \\ Applied Chemistry Department, Urban Environmental Sciences, Tokyo Metropolitan University \\ 1-1 Minami-Ohsawa, Hachioji, Tokyo 192-0397 \\ E-mail:kajii@atmchem.apchem.metro-u.ac.jp
}

(Received January 24, 2008)

\begin{abstract}
To know the air quality of the urban atmosphere, precise measurement of key species is essentially important such as NOx and VOCs because they are very reactive and some of them are toxic. NOx indicates combination of $\mathrm{NO}$ and $\mathrm{NO}_{2}$ molecules. Exhaust of combustion mainly contains NO but it is easily oxidized by either ozone or peroxyl radicals in the atmosphere into $\mathrm{NO}_{2}$. Resultant $\mathrm{NO}_{2}$ is again converted to $\mathrm{NO}$ in the photolysis of solar UV. Thus, $\mathrm{NO}$ and $\mathrm{NO}_{2}$ achieve chemical equilibrium within a couple of minutes in daytime atmosphere. Selective measurement of $\mathrm{NO}_{2}$ is suffered from chemical interference when conversion technique to $\mathrm{NO}$ is applied. Therefore, direct measurement of $\mathrm{NO}_{2}$ is needed such as optical absorption and laser induced fluorescence (LIF) techniques. Although optical absorption technique does not need calibration process but sensitivity is not enough for lower concentration. Thus, we applied LIF technique for detecting NOx family molecules such as $\mathrm{NO}, \mathrm{NO}_{2}, \mathrm{NO}_{3}$, and $\mathrm{N}_{2} \mathrm{O}_{5}$. We present herein instrumentation for both $\mathrm{NO}_{2}$ and $\mathrm{NO}_{3}$ sensors using pulsed laser excitation. We used an SHG of DPSS Nd: $\mathrm{YVO}_{4}$ laser and tunable dye laser pumped by it to measure $\mathrm{NO}_{2}$ and $\mathrm{NO}_{3}$, respectively. The detection limits of radical sensors are 2 ppt for $\mathrm{NO}_{2}$ and 7 ppt for $\mathrm{NO}_{3}$ under some practical conditions. Using this instrument we measured $\mathrm{N}_{2} \mathrm{O}_{5}$ in sub-urban air of Tokyo. Using chemical model analysis we assessed heterogeneous loss processes of $\mathrm{N}_{2} \mathrm{O}_{5}$ on the aerosol surface and discussed chemical fate of NOx emitted in urban atmosphere. Photochemical oxidant formation is becoming great concern as revival issue from 1970's. To investigate photochemical ozone formation process in the atmosphere, $\mathrm{HOx}$ radicals, $\mathrm{OH}, \mathrm{HO}_{2}$, and $\mathrm{RO}_{2}$ radicals, investigation is important as well as NOx measurements and great efforts are paid for detection of such radicals using either chemical ionization mass spectrometry or spectroscopic methods such as LIF. In addition to the information of HOx radicals, reactive VOCs measurements are also necessary for evaluate air quality. However, kind of VOCs existing in the urban atmosphere is believed to be more than 500 . Individual measurements of chemical species are not practical to cover such a large number of molecules. Thus, we proposed to measure $\mathrm{OH}$ reactivity in the atmosphere and assess the air quality using $\mathrm{OH}$ reactivity as an index of pollution or photochemical activity. We present here the developed technique how to measure $\mathrm{OH}$ reactivity in the real atmosphere. We conducted a couple of field expedition using this technique and show some of the results.
\end{abstract}

Key Words: Air quality, LIF, Radicals, OH reactivity, Nitrogen oxydes

\section{Introduction}

Advancement of laser technologies made it possible to measure the atmospheric constituents of trace levels. In order to investigate the phenomena of global change in the atmosphere such as ozone depletion, global warming, acidification of the atmosphere, and photochemical oxidant increase, observations of key chemical species are essential, because in the most of the case, chemical species play key roles and couple together such issues. However, it is not easy to measure either reactive or effective species precisely. The points are sensitivity, selectivity, time and space resolutions. Judging from these requirements laser sensing technique is ideal for atmospheric applications. Concerning specific measurements absorption, fluorescence, and ionization techniques are proposed and extensively applied. To use prominent character of low beam diversion and high spectral resolution, long path absorption technique especially, differential optical absorption spectroscopy (DOSA) is employed to measure trace gases. This technique has advantage that it does not need calibration and provides average concentration along with optical pass. Ionization techniques usually combine mass spectrometryare coupled by laser ionization technique to measure specific volatile organic compounds (VOC) and radical species such as $\mathrm{OH}$ and $\mathrm{HO}_{2}$ radicals. Indeed there are a lot of advantage for this technique such as ultra high sensitivity, and high selectivity. However, due to heavy mass-spec and high consumption of electricity it is not easy for atmospheric application especially 


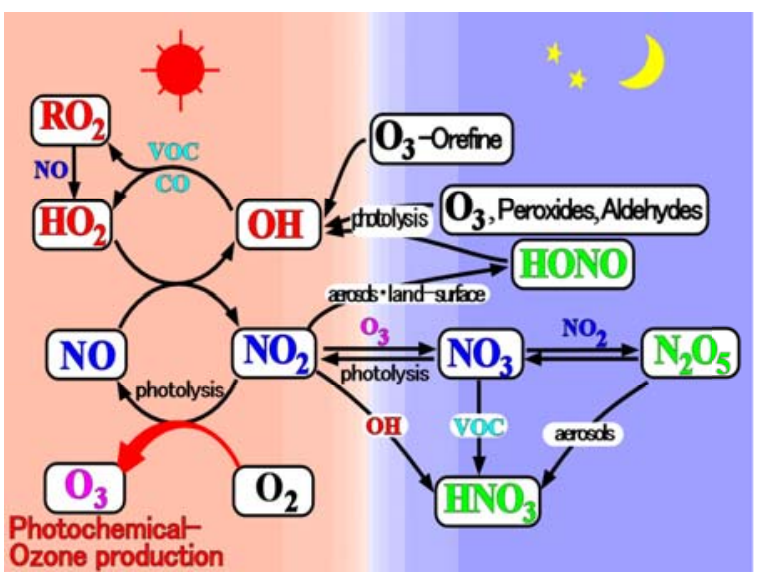

Fig. 1 Reaction mechanism in the urban atmosphere.

in the point of view of portability. Laser induced fluorescence (LIF) technique is also promising technique for ultra low abundant reactive species such as $\mathrm{OH}, \mathrm{NO}, \mathrm{NO}_{2}, \mathrm{Cl}$, $\mathrm{Br}, \mathrm{CO}, \mathrm{PAHs}$, and other molecules. ${ }^{1)}$

To know the air quality of the urban atmosphere, precise measurement of key species is essentially important such as reactive nitrogen oxides $\mathrm{NOy}\left(\mathrm{NO}, \mathrm{NO}_{2}, \mathrm{NO}_{3}\right.$ and $\mathrm{N}_{2} \mathrm{O}_{5}$ ) and $\mathrm{HOx}\left(\mathrm{OH}, \mathrm{HO}_{2}\right.$, and $\left.\mathrm{RO}_{2}\right)$ as shown in Fig.1. ${ }^{2)}$ HOx radicals are extremely important in daytime chemisitry. $\mathrm{OH}$ radicals react almost all trace species except some halgenated species and carbon dioxides. Either $\mathrm{HO}_{2}$ or organic peroxy radicals $\left(\mathrm{RO}_{2}\right)$ is formed by the $\mathrm{OH}$ reaction of carbon monoxide or VOC. These peroxy radicals react with $\mathrm{NO}$ forming $\mathrm{NO}_{2}$ and $\mathrm{OH}$ radical is finally reformed. Formed $\mathrm{NO}_{2}$ is reconverted to NO with ozone formation. This is so called photochemical ozone formation mechanism. VOC and CO are considered as fuel and NOx as catalyzer to accelerate radical chain cycle. On the contrary, $\mathrm{NO}_{3}$ and $\mathrm{N}_{2} \mathrm{O}_{5}$ pray key role in acidification of the nighttime atmosphere. Therefore, vigorus efforts were paid for the detections of NOy and HOx radicals developed by LIF technique.

\section{OH reactivity measurements}

Indeed, information of concentration of each reactive VOCs is important in order to diagnose the air quality, it is impossible to observe full set of VOC in practice. There exits more than 500 kinds of VOCs which react with $\mathrm{OH}$ radical in the atmosphere. ${ }^{3)}$ Individual measurements of chemical species are not practical to cover such large number of molecules. Thus, we proposed to measure $\mathrm{OH}$ reactivity in the atmosphere and assess the air quality suing $\mathrm{OH}$ reactivity as an index of pollution or photochemical activity. To realize this we developed an instrument to measure a lifetime of $\mathrm{OH}$ radical in ambient air by laser-induced pump and probe technique as shown in Fig. 2. $\mathrm{OH}$ radicals are generated in the photolysis of ozone by $266 \mathrm{~nm}$ laser.

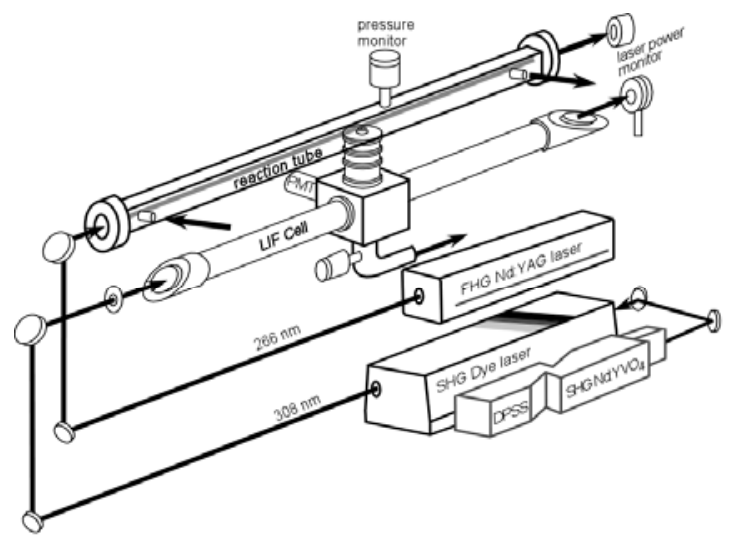

Fig. 2 Pump and probe instrument for $\mathrm{OH}$ reactivity measurement.

Decay of resultant $\mathrm{OH}$ is monitored by LIF-FAGE technique using 308 nm laser. ${ }^{4)}$ Figure 3 shows typical time profiles of $\mathrm{OH}$ radicals. $\mathrm{OH}$ temporal profile of zero air (gray curves) after 266-nm pulse excitation shows two decay components. Faster decay may reflect thermal expansion process due to photolysis laser and slower one shows diffusion process. Both are assigned as physical processes.

In case of ambient air slower decay becomes faster due to chemical reaction while faster decay does not change. From the analysis of these slower decay rates, $\mathrm{OH}$ reactivity is available. Total $\mathrm{OH}$ reactivity which is inverse of lifetime was measured in the ambient air in Tokyo using the developed instrument in order to test the utility of the instrument. It demonstrated that the instrument is practically running well and we succeeded to observe $\mathrm{OH}$ reactivity through the year in
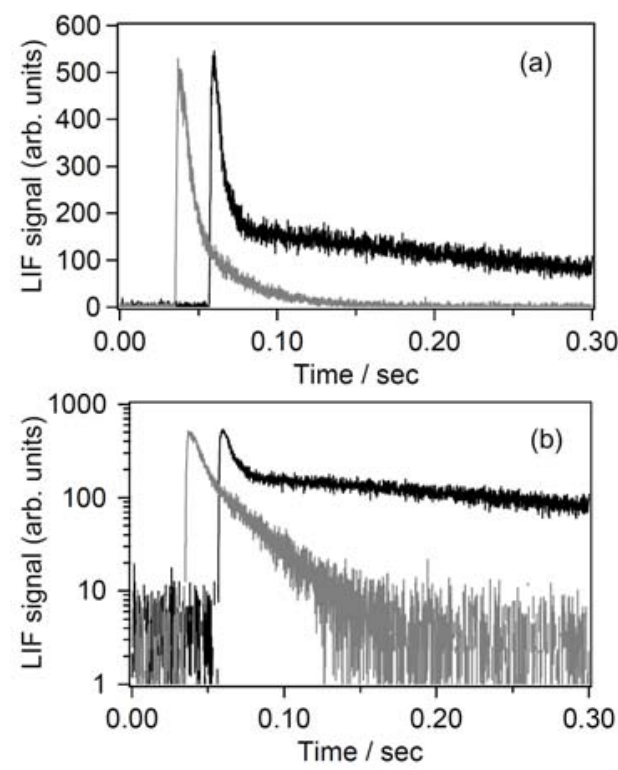

Fig. 3 Examples of the measured $\mathrm{OH}$ decay profile of zero air (solid line) and ambient air (gray line). (a): linear scale. (b): logarithmic scale. 
Tokyo.

We have successfully applied this instrument for real atomspheric observation in Tokyo as well as simultaneous measurements of VOCs by GC technique and proton-transfer mass spectrometory. ${ }^{5)}$ We compared $\mathrm{OH}$ reactivities determined by pump-probe technique and VOC analysis. In case of VOC analysis we considered more than 70 species. Interestingly in spring and summer, we found a lot of discrepancy more than $30 \%$ of $\mathrm{OH}$ reactivity between measured and calculated one. However in winter both data were fairly agreed with each other as seen in Fig. 4(b). From these observation, we have learnt that there exist still gap between our knowledge and real situation in the atmosphere from view point of reactive species and that $\mathrm{OH}$ reactivity is considered as good index for photochemical activity instead of each VOC analysis. ${ }^{6}$

\section{Nitrogen oxides measurements}

Exhaust of combustion mainly contains NO but it is easily oxidized by either ozone or peroxyl radicals in the atmosphere into $\mathrm{NO}_{2}$. Resultant $\mathrm{NO}_{2}$ is again converted to $\mathrm{NO}$ in the photolysis of solar UV. Thus, $\mathrm{NO}$ and $\mathrm{NO}_{2}$ achieve chemical equilibrium within a couple of minutes in daytime atmosphere. Selective measurement of $\mathrm{NO}_{2}$ is suffered from chemical interference when conversion technique to $\mathrm{NO}$ is applied. Therefore, direct measurement of $\mathrm{NO}_{2}$ is needed such as optical absorption and laser induced fluorescence (LIF) techniques. Although optical absorption technique does not need calibration process but sensitivity is not enough for lower concentration. Thus, we applied LIF technique for detecting $\mathrm{NOx}$ family molecules such as $\mathrm{NO}, \mathrm{NO}_{2}, \mathrm{NO}_{3}$, and $\mathrm{N}_{2} \mathrm{O}_{5}$.

We present herein instrumentation for both $\mathrm{NO}_{2}$ and $\mathrm{NO}_{3}$ sensors using pulsed laser excitation. We used an SHG of DPSS Nd: $\mathrm{YVO}_{4}$ laser and a tunable dye laser pumped by the SHG of Nd: $\mathrm{YVO}_{4}$ laser to measure $\mathrm{NO}_{2}$ and $\mathrm{NO}_{3}$, respectively.

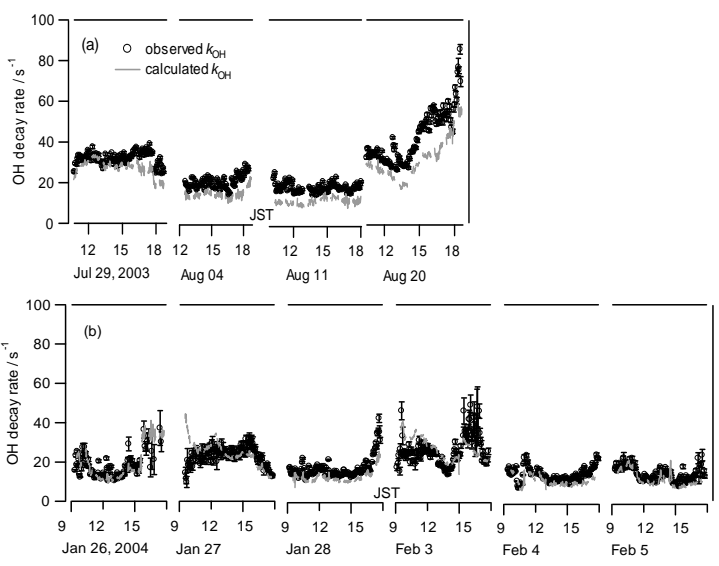

Fig. 4 Observed (open circle) and calculated (gray line) $\mathrm{OH}$ reactivities obtained in sub-urban Tokyo in summer (a) and winter (b).

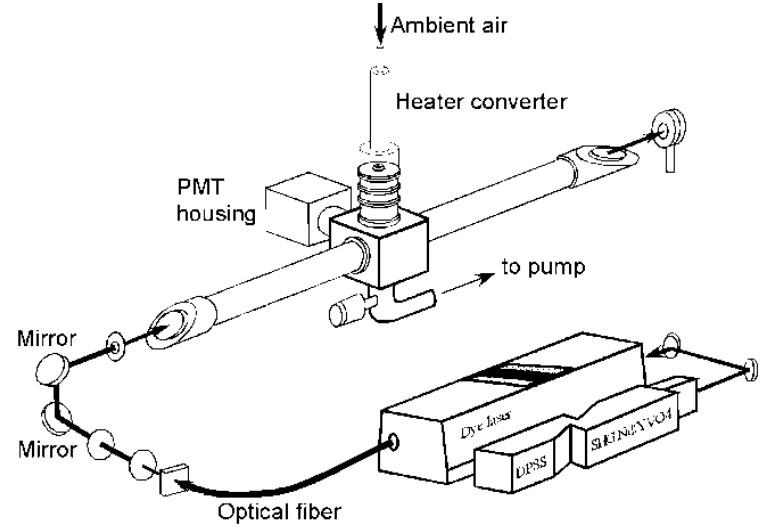

Fig. 5 Instrumental set-up for atmospheric $\mathrm{N}_{2} \mathrm{O}_{5}$ measurement with $\mathrm{NO}_{3}$ sensor using heater converter.

Since $\mathrm{NO}_{2}$ molecule has broad absorption band in visible wavelength, second harmonic wave length is possible to excite it. On the contrary to excite $\mathrm{NO}_{3}$ radicals, it is necessary to tune laser wavelength for the absorption maximum of $\mathrm{NO}_{3}$ radicals. $\mathrm{NO}_{3}$ has characteristic absorption band in both 623 and $662 \mathrm{~nm}$. From several reasons we selected $623 \mathrm{~nm}$ for the excitation of $\mathrm{NO}_{3}$ radicals. The detection limits of radical sensors are 2 ppt for $\mathrm{NO}_{2}$ and 7 ppt for $\mathrm{NO}_{3}$ under some practical conditions. ${ }^{7,8)}$

$\mathrm{NO}_{3}$ react further to $\mathrm{NO}_{2}$ to form $\mathrm{N}_{2} \mathrm{O}_{5}$ in nocturnal atmosphere. $\mathrm{N}_{2} \mathrm{O}_{5}$ is well known to up-taken on the surface of aerosols to form nitric acid. This is almost irreversible reaction. Thus, this process is considered as a major sink of NOx in nigh time. Therefore, $\mathrm{N}_{2} \mathrm{O}_{5}$ observation in night time is essentially important to discuss dynamical behavior of NOx in the atmosphere. However, since it difficulty $\mathrm{N}_{2} \mathrm{O}_{5}$ was hardly observed in the atmosphere up to recently. $\mathrm{N}_{2} \mathrm{O}_{5}$ easily dissociate into $\mathrm{NO}_{2}$ and $\mathrm{NO}_{3}$ using heater tube.

$$
\begin{aligned}
& \mathrm{NO}+\mathrm{O}_{3} \rightarrow \mathrm{NO}_{2}+\mathrm{O}_{2} \\
& \mathrm{NO}+\mathrm{HO}_{2} \rightarrow \mathrm{NO}_{2}+\mathrm{OH} \\
& \mathrm{NO}+\mathrm{RO}_{2} \rightarrow \mathrm{NO}_{2}+\mathrm{RO} \\
& \mathrm{NO}_{2}+h v \rightarrow \mathrm{NO}+\mathrm{O}\left({ }^{3} \mathrm{P}\right) \\
& \mathrm{NO}_{2}+\mathrm{O}_{3} \rightarrow \mathrm{NO}_{3}+\mathrm{O}_{2} \\
& \mathrm{NO}_{3}+\mathrm{NO} \rightarrow 2 \mathrm{NO}_{2} \\
& \mathrm{NO}_{3}+\mathrm{NO}_{2} \rightarrow \mathrm{N}_{2} \mathrm{O}_{5} \\
& \mathrm{~N}_{2} \mathrm{O}_{5} \rightarrow \mathrm{NO}_{3}+\mathrm{NO}_{2} \\
& \mathrm{~N}_{2} \mathrm{O}_{5}+\text { aerosol }\left(+\mathrm{H}_{2} \mathrm{O}\right) \rightarrow 2 \mathrm{HNO}_{3}
\end{aligned}
$$

Thus, $\mathrm{N}_{2} \mathrm{O}_{5}$ observation becomes available if atmospheric $\mathrm{NO}_{3}$ is able to measure. We applied $\mathrm{NO}_{3}$ sensor to measure $\mathrm{N}_{2} \mathrm{O}_{5}$ in sub-urban air of Tokyo using thermal dissociation technique. This was the first attempt to determine concentration of $\mathrm{N}_{2} \mathrm{O}_{5}$ using LIF technique. ${ }^{9)}$

We carried out field experiment of $\mathrm{N}_{2} \mathrm{O}_{5}$ on the top of the building of our campus where is located about $30 \mathrm{~km}$ toward west from the center of Tokyo. Observational periods are 
between July and August on 2005, February on 2006, July and August on 2006. Ozone, CO, NOx, VOCs are simultaneously observed in addition to $\mathrm{N}_{2} \mathrm{O}_{5}$. The obtained concentration of $\mathrm{N}_{2} \mathrm{O}_{5}$ in night time winter was typically a couple of hundred ppt. $\quad \mathrm{N}_{2} \mathrm{O}_{5}$ concentration sometime exceeds $1 \mathrm{ppb}$ during heavily polluted episode with high ozone and NOx.

$\mathrm{N}_{2} \mathrm{O}_{5}$ has quite strong temperature dependence for the dissociation. $\mathrm{N}_{2} \mathrm{O}_{5}$ concentration in winter was systematically higher than that in summer. It is expected to be lower abundant in summer but it sustained with a couple of hundred ppt so far. Using reactions from (1) through (9) and kinetic data from JPL 2002, steady state concentration of $\mathrm{N}_{2} \mathrm{O}_{5}$ was obtained and plotted in Fig. 5 as gray lines. Using box model we estimated loss process of $\mathrm{N}_{2} \mathrm{O}_{5}$. VOCs reaction with $\mathrm{NO}_{3}$

Table 1 Loss rates of $\mathrm{N}_{2} \mathrm{O}_{5}$ and $\mathrm{NO}_{3}$

\begin{tabular}{|c|c|c|c|c|c|}
\hline & $\begin{array}{l}\text { night } \\
\text { hours }\end{array}$ & $\begin{array}{l}\text { Removal } \\
\text { processe }\end{array}$ & $\begin{array}{c}\text { Reactivity } \\
\qquad / \mathrm{s}^{-1}\end{array}$ & $\begin{array}{c}\text { Loss rate } \\
\qquad / 10^{5} \\
\mathrm{~cm}^{-3} \mathrm{~s}^{-1} \\
\end{array}$ & $\begin{array}{c}\text { NOx } \\
\text { loss /ppb } \\
\text { night }^{-1} \\
\end{array}$ \\
\hline \multirow[t]{2}{*}{ summer } & \multirow[t]{2}{*}{10} & $\begin{array}{r}\mathrm{Via} \\
\mathrm{N}_{2} \mathrm{O}_{5} \\
\end{array}$ & $1.2 \times 10^{-4}$ & 2.0 & \multirow[t]{2}{*}{2.0} \\
\hline & & Via $\mathrm{NO}_{3}$ & $1.3 \times 10^{-1}$ & 15 & \\
\hline \multirow[t]{2}{*}{ winter } & \multirow[t]{2}{*}{14} & $\begin{array}{r}\text { Via } \\
\mathrm{N}_{2} \mathrm{O}_{5} \\
\end{array}$ & $1.2 \times 10^{-4}$ & 15 & \multirow[t]{2}{*}{2.3} \\
\hline & & Via $\mathrm{NO}_{3}$ & $1.2 \times 10^{-4}$ & 1.4 & \\
\hline
\end{tabular}

Table 2 NOx loss due to $\mathrm{OH}$ radicals

\begin{tabular}{c|c|c|c|c}
\hline & $\begin{array}{c}{[\mathrm{OH}]} \\
/ \mathrm{pptv}\end{array}$ & $\begin{array}{c}\text { Loss rate / } \\
10^{5} \mathrm{~cm}^{-3} \mathrm{~s}^{-1}\end{array}$ & Day hours & $\begin{array}{c}\text { NOx } \\
\text { loss /ppb } \\
\text { day }^{-1}\end{array}$ \\
\hline summer & 0.04 & 60 & 14 & 15.5 \\
\hline winter & 0.02 & 30 & 10 & 4.3 \\
\hline
\end{tabular}

might be predominant for the loss of NOx in nighttime summer, while heterogeneous reaction of $\mathrm{N}_{2} \mathrm{O}_{5}$ on the surface of aerosols is important in winter. NOx removal via either $\mathrm{NO}_{3}$ or $\mathrm{N}_{2} \mathrm{O}_{5}$ process is determined to be 2.0 and 2.3 ppbv/night in the summer and winter, respectively. Assuming daytime concentration of $\mathrm{OH}$ is 0.04 and $0.02 \mathrm{ppt}$ in summer and winter, respectively, estimated NOx loss by $\mathrm{OH}$ reaction is listed in table 2. Nighttime loss of NOx in winter via either $\mathrm{NO}_{3}$ or $\mathrm{N}_{2} \mathrm{O}_{5}$ rout is comparable with $\mathrm{NO}_{2}+\mathrm{OH}$ reaction in daytime. $\mathrm{N}_{2} \mathrm{O}_{5}$ formation requires two molecules of NOx. Thus, this night time loss process via either $\mathrm{NO}_{3}$ or $\mathrm{N}_{2} \mathrm{O}_{5}$ is important in urban / sub-urban atmosphere.

\section{Acknowledgements}

The author wishes thanks for Drs. Shungo Kato (TMU), Jun Matsumoto (TIT), and Yasuhiro Sadanaga (OPU) for VOCs and radical measurements.

\section{References}

1) A. Fried, D. Richter, J. Plane, A. Saiz-Lopez, R. C. Cohen, E. C. Wood, J. Williams, H. Coe, J. Alan, A. Weinheimer, A. Lewis, J. Hamilton, and A. Hofzumahaus: Analytical Techniques for Atmospheric Measurement (Dwayne Heard, 2006).

2) Y. Sadanaga, J. Matsumoto, and Y. Kajii: J. Photochem. Photobiol. C: Photochemistry Reviews 4 (2003) 85.

3) A.C. Lewis, N. Carslaw, P. J. Marriott, R. M. Kinghorn, P. Morrison, A. L. Lee, K. D. Bartle, M. J. Pilling: Nature 405 (2000) 778.

4) Y. Sadanaga, A. Yoshino, K. Watanabe, A. Yoshioka, Y. Wakazono, Y. Kanaya and Y. Kajii: Rev. Sci. Instrum. 75 (2004) 2648.

5) A. Yoshino, Y. Sadanaga, K. Watanabe, S. Kato, Y. Miyakawa, and Y. Kajii: Atmos. Environ. 40 (2006) 7869.

6) Y. Sadanaga, A. Yoshino, S. Kato, and Y. Kajii: Environ. Sci. Technol. 39 (2005) 8847.

7) J. Matsumoto and Y. Kajii: Atmos. Environ. 37 (2003) 4847.

8) J. Matsumoto, N. Kosugi, H. Imai and Y. Kajii: Rev. Sci. Instrum. 76 (2005) 064101.

9) J. Matsumoto, H. Imai, N. Kosugi, Y. Kajii: Atmos. Environ. 39 (2005) 6802. 